Disponível em

http://www.anpad.org.br/rac

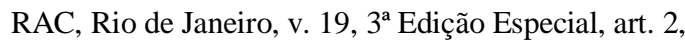
pp. 269-287, Outubro 2015 http://dx.doi.org/10.1590/1982-7849rac20151545

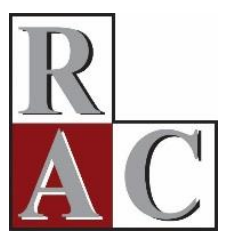

\title{
Contestações sobre o Masculino no Contexto do Trabalho: Estudo Pós-modernista em Mineradoras e Siderurgias
}

\author{
Contestations on Masculinity in the Context of Work: A Post-modernist Study of \\ Mining and Steelworks
}

Eloísio Moulin de Souza

Universidade Federal do Espírito Santo - UFES

Mônica de Fatima Bianco Universidade Federal do Espírito Santo - UFES

Gelson Silva Junquilho Universidade Federal do Espírito Santo - UFES

Artigo recebido em 12.07.2013. Última versão recebida em 02.09.2014. Aprovado em 04.09.2014. Publicado online em 19.11.2014. 


\title{
Resumo
}

No momento sócio-histórico denominado de pós-modernidade, fronteiras sociais anteriormente estabelecidas têm sido destruídas (Bauman, 2001). Nesse contexto, também, impera a crise do masculino, o que provoca um questionamento sobre a masculinidade, bem como quanto ao predomínio dos antigos modelos culturais masculinos nos espaços organizacionais (Amaral, 2005; Brooks, 2010; Robinson, 2000). Este artigo pretende analisar, sob uma perspectiva cultural (Connell, 2004; Prasad, 2012), como as mudanças no masculino têm afetado a divisão do trabalho no setor minerossiderúrgico. Um aspecto relevante é que a maioria dos trabalhos sobre o gênero se dedica a estudar feminilidade como algo inerente à mulher, outro é o estudo do fenômeno masculinidade no ambiente de trabalho. A pesquisa realizada é qualitativa e a coleta de dados foi executada por meio de entrevistas com o uso de um roteiro semiestruturado. Como resultados, observou-se que tem ocorrido mudanças em relação à divisão de trabalho entre homens e mulheres, contudo essas mudanças ocorrem de forma mais acelerada na vida privada do que no ambiente de trabalho. A masculinidade exerce a função de organizadora do trabalho. É atribuída a mulheres, gays efeminados e homens heterossexuais que apresentem atributos femininos, uma incapacidade laboral na execução de atividades de comando e concepção.

Palavras-chave: gênero; masculino; trabalho; mineradora; siderurgia.

\begin{abstract}
The sociohistorical time called postmodernity has destroyed previously established social boundaries (Bauman, 2001). A crisis of masculinity also prevails in this context, provoking a questioning of masculinity, as well as of the predominance of older male cultural models in organizational arenas (Amaral, 2005; Brooks, 2010; Robinson, 2000). Using a cultural approach (Connell, 2004; Prasad, 2012) this article aims to analyze how the changes in masculinity have affected the male division of labor in the mining and steel sector. An important aspect is that most of the work on gender is dedicated to studying femininity as something inherent to women, while another is studying the phenomenon of masculinity in the workplace. This field research was a qualitative one that collected data through semi-structured interviews. Changes were observed to have occurred in relation to the division of labor between men and women, however, these changes occur more rapidly in private life than in the workplace. Masculinity has the function of organizing work. An inability to perform work activities related to command and conceptualization is attributed to women and effeminate homosexual and heterosexual men.
\end{abstract}

Key words: gender; masculinity; work; mining; steelworks. 


\section{Introdução}

Collinson e Hearn (2004) afirmam que trabalho, organização e gestão continuam sendo as maiores forças na construção de homens, mulheres, feminilidades, masculinidades e poder. Na concepção desses autores, o trabalho é de fato socialmente organizado por meio de uma divisão de gênero. Colocado de outro modo, a divisão de gênero e a distribuição do trabalho são fenômenos reais, socialmente variáveis e afetam tanto homens quanto mulheres.

Conforme constatado por Souza, Corvino e Lopes (2013) e Eccel e Grisci (2011), o ambiente das empresas é organizado de forma a manter valores masculinos, onde masculinidade é vista como algo relacionado apenas a homens heterossexuais, cabendo às mulheres e aos homossexuais um papel secundário. Entretanto é sabido que, no momento sócio-histórico denominado de pós-modernidade ou modernidade líquida (Bauman, 2001), fronteiras sociais anteriormente estabelecidas têm sido destruídas. É nesse contexto descrito por Bauman (2001) que também impera a crise do masculino, provocando um questionamento e problematização sobre a masculinidade, bem como sobre o predomínio dos antigos modelos culturais masculinos nos espaços organizacionais. Portanto, diante das instabilidades e mudanças sociais contemporâneas (Boltanski \& Chiapello, 2009), torna-se relevante entender as ressignificações da masculinidade e como elas afetam as pessoas nas organizações.

Diante do exposto, este artigo $^{(1)}$ pretende analisar como a crise do masculino tem afetado a clássica divisão do trabalho entre concepção e execução (Braverman, 1987) no setor minerossiderúrgico. Vale salientar que feminilidade e masculinidade são construções sociais, ou seja, ideias culturais quanto ao que se considera adequado para homens e mulheres e que funcionam como normas na busca pela congruência entre trabalho realizado e gênero (Billing, 2011). Logo, intenta-se entender como se manifestam, no setor minerossiderúrgico do Espírito Santo, mudanças relacionadas à percepção da masculinidade sob a ótica de trabalhadores homossexuais e heterossexuais e suas possíveis implicações/correlações com a organização do trabalho entre homens, mulheres e homossexuais. A discussão da temática masculinidade por si só torna-se relevante, pois, além da maioria dos trabalhos sobre gênero dedicar-se a estudar feminilidade, muitos deles consideram feminilidade como algo inerente à mulher, perspectiva conceitual da qual este artigo se afasta, conforme será explicitado posteriormente. Outro aspecto relevante é o estudo do fenômeno masculinidade focalizado no ambiente de trabalho, e não na sociedade como um todo.

Vale ressaltar, ainda, que a maioria das pesquisas da área de Administração relacionadas ao estudo do masculino são estudos sobre consumo em diferentes vertentes (Cupolilo, 2008; Davidovitsch \& Silva, 2008; Fontes, Borelli, \& Casotti, 2010; Sauerbronn, 2007; Veiga \& Matos, 2008). Entretanto esses estudos não consideram o poder em suas análises e não problematizam questões conceituais relacionadas à definição de masculinidade, apresentando-se como acríticos nesses aspectos.

Assim, para cumprir o seu intento, este artigo discute os principais conceitos relacionados a gênero e masculinidade numa perspectiva construcionista social, evidenciando as implicações e relações existentes entre gênero e trabalho, bem como essas mesmas relações produzem discriminações e hierarquias sociais. Num segundo momento, problematiza-se o conceito de masculino a partir da crise do masculino vivenciada na contemporaneidade. Em seguida, é apresentada a metodologia da pesquisa e a análise dos dados produzidos. Por fim, as principais conclusões são evidenciadas.

\section{Gênero e Sexualidade: A Construção Social da Masculinidade}

Foucault (1988) afirma que a diferenciação pelo sexo é um dos dispositivos do biopoder, sendo o biopoder um elemento indispensável para o desenvolvimento do capitalismo. Fez-se necessário ao sistema aumentar a utilidade, a docilidade dos corpos, bem como as forças, as habilidades e a vida em geral, assim, tornando-se mais fácil a sujeição das pessoas aos valores capitalistas. Esses mesmos valores 
exercem o poder para segregar e simultaneamente hierarquizar a sociedade, assim, provocando efeitos de hegemonia.

De acordo com Bordieu (2010), instaurou-se uma diferença universal dos corpos entre homens e mulheres, a qual contribui para uma dada naturalização da mesma. Para o autor, a divisão de sexos apresenta-se como uma "ordem das coisas, como se diz por vezes para falar do que é normal, natural" (Bordieu, 2010, p. 17). Dessa forma, essa "experiência apreende o mundo social e suas arbitrárias divisões, a começar pela divisão socialmente construída entre os sexos, como naturais, evidentes, e adquire, assim, todo um reconhecimento de legitimação" (Bordieu, 2010, p. 17).

Muraro (2007) salienta que, em relação a gênero, todos nós temos feminino e masculino, ou seja, gênero não é algo biológico. Scott (1990) faz uma crítica ao determinismo biológico e à incomensurabilidade nas relações entre os sexos. Sobre este aspecto, Oliveira (2008) refere que a masculinidade é "enquanto lugar simbólico/imaginário, fundamental aos processos de subjetivação, ligada a uma estrutura relacional na qual se apoia a questão da identidade/alteridade, além de ter por base um sistema de valores e de procedimentos comportamentais sancionados pela sociedade" (p. 175).

Assim, os estudos de gênero não estão somente relacionados às mulheres, mas preocupam-se também com homens, ou seja, pela esfera de produção tanto de homens quanto de mulheres (Holter, 2004). E isso remete às seguintes afirmações: masculino não significa homem, como também feminino não é sinônimo de mulher. Ambos, masculino e feminino, são produtos socialmente construídos, transcendendo o sexo biológico, sem relação direta com o mesmo. Neste sentido, masculino e feminino não podem ser pensados como sendo produtos culturais excludentes, antagônicos e binários entre si (Prasad, 2012). Por exemplo, Edwards (2004) coloca que, ao longo dos séculos, gays e masculinidade foram entendidos como antagônicos, sendo os gays associados à efeminação.

Souza e Pereira (2013) salientam que a hegemonia, considerada como normal, está associada a uma vivência masculina heteronormativa, na qual inclusive sujeitos homossexuais buscam não se reconhecer como gays efeminados, diferenciando-se enquanto homossexuais. Assim, reafirmam evidências de uma hierarquia social na qual gays que não fazem coisas de homem são discriminados por outros homossexuais como sendo mais efeminados. Há casos em que gays erotizam homens e valorizam a presença de características masculinas, em oposição às femininas, ou, ainda, a rejeição, por muitos gays, da efeminação em favor de uma hipermasculinidade (Edwards, 2004). Embora desejo por pessoas do mesmo sexo seja algo presente em todos os tempos e espaços, o homossexual como um tipo de identidade existe há pouco mais de um século (Edwards, 2004).

A hierarquia de masculinidades não ocorre somente entre homossexuais. Por exemplo, Eccel e Grisci (2010) analisaram a figura do engenheiro como representante da masculinidade hegemônica. Tal figura é entendida como racional, objetiva e dotada de domínio técnico. Em outro artigo, Eccel e Grisci (2011) mostram o ambiente de trabalho como produtor de uma masculinidade ideal, revelando novas relações de poder entre os gêneros, inclusive de dominação entre o masculino hegemônico e outras formas de masculino. Conforme Connell (1995), masculinidade não é algo fixo, mas algo que muda no tempo e lugar. As masculinidades são histórica, cultural e temporariamente contingentes. Para Morrell e Swart (2004), os estudos pós-coloniais, ao intentarem capturar a fluidez de uma vida pós-colonial e suas multiplicidades, contribuem para um conceito plural de masculinidade, pois a teoria pós-colonial é fortemente subversiva em relação aos essencialismos. Holter (2004) divide os estudos sobre masculinidade em dois campos: (a) teorias de hierarquia de gênero e (b) teorias sobre a desigualdade estrutural. Ambas são perspectivas construcionistas sociais, fato que as caracteriza como divergentes e antagônicas das afirmações sociobiológicas que emergiram aproximadamente há três décadas sobre o tema. Enquanto as teorias de hierarquia de gênero enfatizam em seus estudos aspectos relacionados à dominação masculina, as teorias de desigualdade estrutural estão preocupadas com as relações socioestruturais que envolvem as desigualdades ou discriminações de gênero.

As teorias sobre hierarquia de gênero foram as primeiras reações à neutralização de gênero e a certas perspectivas das ciências sociais que ignoraram as relações entre gênero e poder. Entretanto, apesar de essas contribuições realçarem a visão de masculinidade como uma construção social, há uma 
tendência dessa abordagem em tratá-la como algo homogêneo, estático e sólido. Holter (2004) afirma que, para as teorias de desigualdades estruturais, a masculinidade é flexível e, assim, não se pode tratar qualquer sistema de gênero como universal. Ao invés disso, deve ser visto como construído por uma forma específica de sociedade e pela história, que operam mudando as diversas formas de significados que produzem desigualdades de gênero e criam certos tipos de masculinidades, bem como os caminhos pelos quais o poder é aí vinculado. Assim, diante da flexibilidade de gênero, qual a relação existente entre gênero e trabalho? Como relações de gênero afetam o trabalho e são afetadas por ele?

Conforme abordado anteriormente, trabalho e gestão continuam sendo forças atuantes na construção de homens, mulheres, feminilidades, masculinidades e poder (Collinson \& Hearn, 2004). Segundo Morrell e Swart (2004), as masculinidades modernas foram profundamente construídas em torno do trabalho, as quais proporcionaram um status para os homens. Medeiros e Valadão (2009) evidenciam como as atribuições de masculinidade e feminilidade influenciam o significado de ser homem e mulher nas organizações, nas quais os cargos mais relevantes ficam predominantemente com os homens.

O mesmo acontece com o discurso sobre empreendedorismo. A atividade empreendedora é tomada como independente do gênero. Entretanto, fundamentado na tese neoliberal como puramente meritocrático aberto e acessível a todos, na qual apenas os esforços pessoais determinariam os resultados obtidos, o empreendedorismo é concebido como uma atividade essencialmente masculina. Desse modo, mulheres empreendedoras são consideradas deficientes na atividade e, constantemente, tidas como homens incompletos (Ahl \& Marlow, 2012). Para Devreux (2005), a divisão do poder apoia-se sobre a divisão sexual do trabalho e na categorização social. A categorização seria exercida por meio de um conjunto de fatores que se associam à divisão sexual do trabalho. Na categorização, há uma invenção, criação e reafirmação de categorias sexuadas. Tal fato pode ser exemplificado por Cramer (2009), ao perceber a pouca representatividade de homens entre os profissionais de enfermagem e a discriminação da presença de homens nessa função, sendo os homens enfermeiros tachados como homossexuais ou efeminados. Além disso, a medicina é vista como mais confiável pelos pacientes quando exercida por homens, que, não obstante, dominam os cargos de direção de hospitais (Cramer, 2009). De forma quase que complementar, o artigo de Alves, Brito, Melo, Lemos e Ferreira (2008) evidencia as desproporções de poder entre os gêneros, novamente ilustradas pela predominância de homens em posições gerenciais de chefia em hospitais e mulheres em gerências intermediárias. Resultados equivalentes foram encontrados por Vilas Boas, Paula e Cramer (2003), ao pesquisarem uma revenda de automóveis.

Desse modo, não somente mulheres são discriminadas por executarem atividades consideradas masculinas, como também homens em atividades relacionadas ao cuidar. Áreas de atividades que envolvem o cuidar do outro são socialmente associadas como estritamente de mulheres. Assim, homens que atuam nestas áreas podem sofrer formas particulares de discriminação de gênero. Nesse sentido, desigualdade de gênero pode ser vista como uma relação variante ao invés de uma linha de divisão universal que cria duas categorias de gênero.

A divisão de gênero no trabalho para Connell (2004) faz com que o mundo do trabalho seja culturalmente definido como um domínio dos homens. Contudo isso tem um preço para os homens, pois o homem adulto que não possui trabalho regular é percebido como não tendo chegado completamente a uma masculinidade adulta. Aliás, segundo o autor, os atuais e altos níveis de desemprego existentes em diversos países, bem como a maior participação das mulheres em empregos formais, têm contribuído para minar este conceito de masculinidade fundamentado no trabalho, gerando uma crise identitária.

Holter (2004) afirma que homens com baixo status são mais envolvidos em discriminações de gênero que homens com alto status social. Assim, gênero opera como um sistema de supressão tanto de mulheres como de homens não dominantes, ou seja, produz desigualdades não somente entre homens e mulheres, mas também entre homens e entre mulheres. Por exemplo, Ekenstam, Hohansson e Kuosmanen (2001) salientam que sanções sociais ligadas à formação da masculinidade enfatizam a importância de que um dos seus atributos é não falhar, o que cria um medo generalizado entre os homens de falharem na vida, seja no trabalho ou na realização do ato sexual. Neste sentido, Jerusalinsky 
(2005) salienta que, no imaginário social, a masculinidade é atribuída como sendo ativa e a feminilidade como passiva.

De acordo com Collinson e Hearn (2004), existem múltiplas masculinidades e gêneros masculinos, manifestados no local de trabalho. Esta heterogeneidade tem sido ressaltada nos estudos recentes sobre homens nas organizações. Evidenciam-se, desse modo, aspectos que marcam a natureza performática do gênero (Mathieu, 2009). Ou seja, a ideia de um fazer, uma performance nas/das relações de gênero ou, ainda, um fenômeno social em movimento, em fluxo, praticado na vida cotidiana. Portanto, em função das mudanças contemporâneas relacionadas à construção social da masculinidade, o próximo tópico discute a crise do masculino.

\section{A Crise do Masculino}

A modernidade é o período das grandes narrativas. Entre elas, encontra-se a narrativa da masculinidade "enquanto discurso fundante de uma determinada ordem de valores, que até o fim da modernidade não fez mais que consolidar" (Oliveira, 2008, p. 173). Mees (2005) também esclarece que, na modernidade, a noção de masculino tinha identidade garantida e estava associada à solidez como imagem do membro masculino em ereção, durável pela geração de filhos, associado, desta forma, a algo potente e estável. Na modernidade, "aos homens cabiam as certezas, a inscrição no espaço público como lugar de fala e reconhecimento: às mulheres, o privado" (Mees, 2005, p. 153). Contudo, para o mesmo autor, esta solidez e certeza em relação a gênero não existem mais. Knights e Tullberg (2011) indicam que todas as identidades de gênero são inseguras e frágeis. Entretanto as identidades masculinas sofrem uma fragilidade adicional exatamente devido às expectativas sociais sobre o que é ser um homem: independente, vencedor, provedor familiar, inexpugnável e indestrutível.

Portanto a expressão crise do masculino significa mudanças sofridas na construção de identidades de gênero que rompem com concepções anteriores tidas como estáveis, fixas e bem delimitadas sobre o masculino (Brooks, 2010), buscando-se evidenciar suas contradições e paradoxos. A expressão crise do masculino é usada para enfatizar mudanças nos antigos referenciais que serviram de ordenadores da nossa cultura em relação aos lugares que cada um deveria ocupar como homens e mulheres (Amaral, 2005). Assim, a expressão crise do masculino não significa que a posição do masculino como gênero hegemônico está em perigo na atualidade (Robinson, 2000), nem uma perda de potência do masculino (Amaral, 2005). Neste sentido, Amaral (2005) coloca uma questão: será que a mulher, ao sair da vida doméstica, masculinizou-se, ganhou mais potência, e o homem, ao entrar na vida doméstica, feminizouse, perdeu potência? A autora responde que isso não é verdade e acrescenta que muitos "homens parecem aliviados e achando um grande ganho essa possibilidade de circular entre o feminino e o masculino sem perderem a direção do seu desejo" (Amaral, 2005, p. 96).

Para Connell (2004), o mundo globalizado contemporâneo vem sofrendo muitas mudanças que têm criado instabilidades nos arranjos de gênero. Estas instabilidades, por sua vez, têm produzido os seguintes movimentos: (a) contestação da cultura organizacional sexista e do network de trabalho formado completamente por homens, por meio da ascensão de mulheres em cargos políticos e seus altos níveis de educação; (b) a quebra das identidades sexuais que produziram políticas queer e outros desafios para as identidades gays; (c) a produção e defesa de políticas pró-feministas entre homens heterossexuais; e (d) as imagens de um novo homem mais sensível nos meios midiáticos.

Connell (2004) demonstra que a circulação de diversas identidades gays é um importante indicador de que formas, não hegemônicas de masculinidade, operam e alteram arenas globais. Morrell e Swart (2004) afirmam que os homens jovens brasileiros estão mais flexíveis quando comparados aos homens de sua prévia geração, em relação a expectativas de suas identidades sociais. Conforme Nolasco (1993), a forma opressiva pela qual os homens brasileiros são tradicionalmente socializados em seu relacionamento com trabalho, seja consigo mesmo ou com parceiros, amigos e crianças, ocasiona alguns questionamentos sobre os parâmetros sociais que definem o que é um homem. Estes estereótipos sociais 
sobre o que é um macho de verdade tentam inculcar valores, tais quais: homens não choram, devem ser melhores em tudo e competir, serem fortes e não demonstrarem envolvimentos de fundo emocional. Contudo há um aumento de homens procurando outras formas de subjetividade que não classifiquem as emoções de acordo com uma referência sexista, na qual as emoções são perigosas e irracionais.

Gutmann e Vigoya (2004) demonstram que novas formas de masculinidade têm entrado em choque com formas tradicionais. Segundo Jerusalinsky (2005), a obra de Oscar Wilde é precursora ao apontar as ambiguidades do masculino. Para o autor, não há nenhuma relação entre a ação e a estética masculina, apenas uma relação ficcional, ou seja, "esteticamente alguém pode ser homem, integralmente homem, assim de gravata, ... e embora isso, no ato sexual ter uma prática bem dissimile de sua estética. Muitos dos homens de hoje em dia estariam de acordo com isso" (p. 21). Jerusalinsky (2005) ainda aponta que os metrossexuais são um exemplo vivo desta discrepância entre ato e estética.

Cabistani (2005) salienta que "os efeitos da linguagem nos inscreve na ordem simbólica, antes que possamos escolher qualquer coisa" (pp. 67-68). Desta forma, "homem ou mulher são designações que recebemos a partir dessa 'mínima diferença' inscrita em nossos corpos" (Cabistani, 2005, p. 68). Segundo Cabistani (2005), o sujeito só pode se dizer homem quando o grupo homens comportar elementos pertencentes ao grupo mulheres, e vice-versa, ou seja, elementos pertencentes aos dois grupos estão presentes tanto em homens quanto em mulheres. Entretanto, de forma antagônica, os sujeitos são constantemente cobrados a buscar uma identificação sexual, na qual cada sexo seria visto como oposto, sendo que a identificação só pode acontecer à custa do recalcamento tanto do feminino para os homens quanto do masculino para as mulheres. Na ótica de Cabistani (2005)

Na modernidade o lugar da masculinidade era aparentemente definido em contraste com a feminilidade, mas hoje, tempo que alguns autores nomeiam como modernidade tardia e outros como pós-modernidade, quando há um compartilhamento da esfera pública por homens e mulheres, a diferença não pode mais ser demarcada nesse campo [diferença sexual]. (p. 71).

De acordo com Amaral (2005), o masculino e o feminino não são opostos e excludentes, eles se misturam num indivíduo e estão sujeitos a grandes flutuações. Além disso, a autora esclarece que não se considera o passivo como sendo algo referente à feminilidade e o ativo à masculinidade. E conclui que "os lugares feminino e masculino são uma construção. E, nessa construção, os significantes homem e mulher, por corresponderem à anatomia, não são suficientes para dar conta da declaração de sexo" (Amaral, 2005, p. 91). Vasconcelos, Vasconcelos e Mascarenhas (2004) denominam a diferença de atribuições ou interpretações entre os sexos de falso paradoxo, uma vez que tratam as dimensões racionais e emocionais, características masculinas e femininas, respectivamente, como desvinculadas e incompatíveis. Para Amaral (2005), não se pode falar de masculinidade sem falar de mulheres, nem falar de feminilidade sem falar de homens.

\section{Caminhos Metodológicos Percorridos}

A pesquisa que originou este artigo é do tipo qualitativa. Entenda-se pesquisa qualitativa como uma forma de procurar respostas para questões particulares em contextos sociais específicos, como, por exemplo, o trabalho no setor minerossiderúrgico estudado. Dessa forma, a pesquisa qualitativa se preocupa, dentro das ciências sociais, com um nível de realidade que não pode ser quantificado (Minayo, Deslandes, Cruz, \& Gomes, 1994). Para participar da pesquisa, os sujeitos tiveram de cumprir um prérequisito: trabalhar em empresas do setor minerossiderúrgico há pelos menos cinco anos. O período de cinco anos foi delimitado por entender-se que este tempo de vivência específico no contexto do trabalho estudado é necessário para que os entrevistados tenham vivenciado e possam relatar de forma mais detalhada suas experiências relacionadas à masculinidade, circunscritas ao setor estudado. Foram entrevistados 20 trabalhadores que exercem suas atividades laborais no setor minerossiderúrgico da grande Vitória/ES. Desse quantitativo, 11 foram indicados por membros vinculados ao núcleo de pesquisa. Dois desses 11 sujeitos indicaram os nove restantes, utilizando-se a técnica da Bola de Neve.

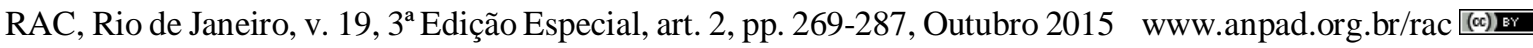


Um indicou mais outros dois que trabalham na mesma empresa, mas atuam em áreas e funções diferentes. Um segundo, entre aqueles 11 sujeitos, indicou mais sete que trabalhavam na mesma empresa, entretanto sem compartilhamento de convívio social e de posições hierárquicas inferiores na estrutura organizacional. É importante ressaltar que, na técnica da Bola de Neve, os entrevistados indicavam outros profissionais do setor passíveis de serem abordados mediante os critérios estabelecidos para a pesquisa: possuir no mínimo cinco anos de trabalho no setor minerossiderúrgico e residir na região metropolitana da grande Vitória. Os entrevistados foram denominados de $\mathbf{E}$ recebendo numeração de 01 até 20 para os diferenciarem (E01 até E20).

Os 20 entrevistados trabalham em três empresas diferentes, sendo duas delas transnacionais de grande porte e uma nacional de grande porte. Foi apresentado para os entrevistados o Termo de Consentimento Informado para Participação em Pesquisa, que esclarece que serão preservados o sigilo das informações e a identidade dos participantes, informando que os registros das informações poderão ser utilizados para fins exclusivamente científicos e divulgação em congressos e publicações científicas, resguardando-se sempre o anonimato dos participantes. Assim, os esclarecimentos prestados pelo Termo de Consentimento e o fato de as entrevistas terem sido executadas fora do ambiente de trabalho permitiram que os entrevistados expressassem seus discursos de forma mais espontânea.

Para tanto, utilizou-se um roteiro semiestruturado de perguntas composto por três blocos de perguntas: (a) História de Vida Pessoal e Profissional, (b) Ambiente do Trabalho e Modelos de Gestão Adotados e (c) Divisão do Trabalho e Crise do Masculino. A informação sobre a sexualidade dos entrevistados foi obtida por meio de autodeclaração dos mesmos. Do total de entrevistados, 16 são homens e quatro são mulheres, com idade variando entre 24 e 58 anos. O pequeno número de mulheres entrevistadas pode ser atribuído ao número reduzido de mulheres que trabalham no setor em relação ao de homens. O tempo de trabalho no setor minerossiderúrgico dos entrevistados varia entre cinco e 34 anos. Com relação à escolaridade, um entrevistado possui mestrado, cinco trabalhadores possuem nível superior e também pós-graduação, quatro pesquisados têm nível superior completo sem serem pósgraduados, cinco sujeitos possuem nível superior incompleto e cinco entrevistados têm ensino médio técnico. Quando indagados sobre o exercício de sua sexualidade, um trabalhador declarou-se bissexual, três declararam-se homossexuais e 16 afirmaram ser heterossexuais.

Por ser a masculinidade um produto cultural que pode ser consumido e produzido por todos, não faz sentido atribuir e aplicar este produto heterogêneo e múltiplo como pertencente apenas aos homens, principalmente heterossexuais. Conforme Edwards (2004) salientou, não existe antagonismo entre homossexualidade e masculinidade. Enfim, masculinidade é aqui vista como um constructo social que pode ser problematizado tanto em relação a homens quanto a mulheres e homossexuais (Edwards, 2004). Por este motivo foram entrevistados homens, mulheres, heterossexuais e homossexuais para discorrerem sobre o masculino.

Esta pesquisa qualitativa utilizou entrevistas semiestruturadas como instrumento de coleta de dados. Entende-se o número de 20 sujeitos pesquisados como suficiente para não se perder o rigor científico na análise, pois, conforme Glaser e Strauss (1967), em pesquisas que utilizam entrevistas como instrumento de coleta de dados, por meio de um quantitativo de 19 entrevistados, atinge-se a saturação teórica. Já Alexandersson (1994) afirma que, em pesquisas interpretativas, a saturação de categorias de análise ocorre com 20 entrevistados.

Antes da realização das entrevistas, o entrevistador explicou de forma geral a pesquisa para os entrevistados. As entrevistas foram gravadas e duraram em média 94 minutos. Posteriormente, foram tratadas por meio de transcrição integral. Os relatos obtidos foram analisados utilizando-se a técnica de análise do discurso. Entretanto existem diversas correntes de pensamento intituladas análise de discurso. Assim, esta pesquisa utilizou a análise de discurso desenvolvida por Foucault (1996).

Foucault não enxerga o discurso e o próprio homem como algo pronto, acabado, fixo e estático, nem como possuindo uma essência. O principal intento de Foucault é caminhar em direção a uma análise histórica do discurso. Nesse sentido, Foucault (1996) leciona que o importante em uma análise do discurso é "saber quais as condições impostas a um sujeito qualquer para que ele possa se introduzir, 
funcionar, servir de nó na rede sistemática do que nos rodeia" (pp. 30-31). Foucault não acredita em um sujeito cognoscente e autônomo, consequentemente, não acredita em um sujeito criador do discurso. Levando-se isso em consideração, a análise do discurso não tem como objetivo e ponto central a análise que partiria do sujeito para explicar suas relações com o mundo externo. A análise do discurso pretende investigar a existência de certos objetos que se desenvolvem, funcionam e modificam-se sem qualquer referência a algo considerado como intuitivo e fundamentado em um sujeito.

Baseando-se nesses princípios, a análise focaliza "como se formaram, através, apesar, ou com o apoio desses sistemas de coerção, séries de discursos; qual foi a norma específica de cada uma e quais foram suas condições de aparição, de crescimento, de variação" (Foucault, 2003, pp. 60-61) de um acontecimento discursivo. Foucault (1996), aborda e explica com clareza, numa entrevista o que seria esse conceito. Para o autor, o acontecimento discursivo nos remete a uma forma de se entender a própria dinâmica da vida, pois, uma vez eliminadas todas as formas de continuidade da história e, consequentemente, da vida, a ordem cronológica da história é quebrada e todo um domínio é liberado. Esse domínio passa a ser algo imenso, contudo, definível, sendo constituído por todo o conjunto de todos os enunciados, sejam eles discursivos ou não discursivos.

Foucault (2003) enfatiza que a análise do discurso por ele desenvolvida não se fundamenta nos métodos da linguística. O que interessa para Foucault (2003) é a função que se pode atribuir quando algo é dito em um determinado momento e espaço. Em outras palavras, uma análise de discurso deve "estabelecer e descrever as relações que esses acontecimentos - que podemos chamar de acontecimentos discursivos - mantêm com outros acontecimentos que pertencem ao sistema econômico, ou ao campo político, ou às instituições" (Foucault, 2003, p. 256). Entre os diversos objetos que funcionam de forma intuitiva e fundamentada em um sujeito, este artigo analisou o objeto masculinidade. Portanto se procurou analisar, a partir dos discursos, qual é a função exercida pela masculinidade quando a analisamos conjuntamente a acontecimentos econômicos e institucionais relacionados ao trabalho. Isto é, qual é a função que a masculinidade exerce no nó da rede do trabalho (acontecimentos econômicos) em organizações mineradoras e siderúrgicas (acontecimentos institucionais), procurando entender seus efeitos na divisão do trabalho entre concepção e execução, bem como a produção de hierarquias sociais no contexto do trabalho analisado.

\section{A Perspectiva dos Trabalhadores sobre a Crise do Masculino e seus Efeitos na Divisão do Trabalho}

Vale relembrar que a expressão crise do masculino representa as mudanças ocorridas na construção de identidades de gênero que buscam romper com concepções anteriormente vistas como estáveis, fixas e bem delimitadas sobre o masculino (Brooks, 2010). Em relação à crise do masculino, os entrevistados entendem que atributos relacionados ao masculino não são os mesmos de épocas atrás. Assim, para melhor esclarecer tal afirmação, a análise sobre as mudanças no masculino será dividida em dois temas: (a) aspectos sociais mais gerais sobre o masculino e (b) aspectos diretamente relacionados ao campo do trabalho no setor minerossiderúrgico. Vale salientar que, devido aos efeitos da linguagem descritos por Cabistani (2005), muitos trabalhadores entendem masculino como sinônimo de homem e feminino de mulher. Conforme Devreux (2005) demonstra, a primeira forma de divisão de poder ocorre na categorização dos sujeitos em homens e mulheres, ou seja, a categorização faz funcionar um conjunto de práticas que se associam à divisão sexual do trabalho.

\section{Aspectos sociais gerais sobre a crise do masculino}

Os próximos parágrafos pretendem debater as mudanças na produção e concepção do masculino. Desta forma, os aspectos sociais gerais sobre a crise do masculino que se evidenciam nos discursos dos sujeitos estão relacionados às mudanças na concepção e produção de masculinidade na sociedade. Os discursos analisados apontam que as principais mudanças em relação ao masculino estão relacionadas à 
suavização da masculinidade, não determinismo entre heterossexualidade e masculinidade e, por fim, mudanças no espaço doméstico.

Em relação aos aspectos sociais sobre as mudanças referentes ao masculino, pode-se destacar que os principais pontos salientados pelos trabalhadores estão relacionados à suavização. Portanto os trabalhadores entrevistados acreditam que atributos relacionados ao masculino sofreram uma suavização em relação às concepções anteriores de masculino. Os entrevistados sublinharam que características anteriormente valorizadas, como, por exemplo, ter um comportamento machista em relação às mulheres, relacionar-se com as pessoas de forma dominadora e agressiva (brutalidade), agir de forma autoritária no dia a dia, são consideradas menos presentes no masculino atual. $\mathrm{O}$ trabalhador E08 afirma "que hoje o masculino está cada vez mais feminino". Apesar de E16 ainda relacionar o conceito de masculino apenas aos homens, ele salienta que "houve uma suavização, não quer dizer que isso seja mais fácil, não é uma facilitação não, entendeu, uma suavização, é... Era cobrado do homem uma atitude firme positiva, o tempo todo, o homem não podia vacilar".

Por isso, Prasad (2012) afirma que masculino e feminino não podem ser pensados como sendo produtos culturais excludentes, antagônicos e binários entre si. A suavização do masculino enfatiza a presença mais evidente de atributos culturais considerados femininos na construção contemporânea de masculinidade, evidenciando que a clássica divisão entre masculino e feminino com suas fronteiras bem delimitadas é um falso paradoxo (Vasconcelos, Vasconcelos, \& Mascarenhas, 2004). Hoje o "homem chora, o homem ri, o homem sente, diz que sente prazer e diz que precisa do prazer" (E19). O masculino é, atualmente, "mais brando. Antigamente, o masculino era aquele homem que tinha a razão, era tudo, a mulher tinha que abaixar a cabeça e nada mais" (E11). Em seu discurso, E08 também enuncia que "hoje o homem é muito mais sensível, o homem é muito mais educado, ele é muito mais polido do que era antes".

Neste sentido, Gutmann e Vigoya (2004) afirmam que, nos últimos anos, novas formas de masculino têm emergido e que as mesmas têm entrado em choque com as formas tradicionais. Connell (2004) esclarece que a instabilidade do mundo atual manifesta-se nos arranjos de gênero, nos quais a imagem de um novo homem mais sensível está presente em diversas mídias. Morrell e Swart (2004) afirmam que os jovens brasileiros estão mais flexíveis quando comparados a homens de sua geração prévia. Nolasco (1993) também acredita que o homem brasileiro tem procurado outros tipos de subjetividades que permitam o exercício de suas emoções, não se limitando aos estereótipos sociais sobre o que é um macho de verdade. Para exemplificar este fato, o entrevistado E20 evidenciou o seguinte:

"Olha ser masculino na década de sei lá, o início do século é ser tudo isso que eu falei antes e muito mais, com muito mais força, ser masculino hoje eu acho que... Os homens se deixam emocionar. Coisa que antigamente não tinha, o homem não podia chorar, o homem não podia se emocionar".

Esta suavização do masculino também se apresenta no corpo, pois o corpo masculino passou a incorporar elementos anteriormente considerados apenas como possíveis em corpos femininos. Os entrevistados deixam claro que cuidar do corpo, por meio de exercícios físicos e produtos de beleza, é preocupação presente na atualidade na construção de masculino (Jerusalinsky, 2005). E06 deixa evidente esta suavização do corpo pela preocupação demonstrada por ele em diminuir a presença de pelos corporais, tentando com isso apresentar um corpo menos bruto: "cada vez menos pelo no homem, cada vez menos pelo ... porque a gente tá perdendo por causa de não precisar mais, usar roupa, não precisa mais ser tão peludo porque a gente não passa frio".

Um dos aspectos interessantes apontados como uma ruptura com modelos de masculinidades anteriores é a relação entre sexualidade e masculinidade. Os entrevistados não relacionam mais a heterossexualidade como elemento central definidor da masculinidade. Neste sentido, não existe antagonismo algum para os entrevistados entre homossexualidade e masculinidade. Sobre este aspecto, E07 enuncia que "a pessoa pode ser masculina, mas não necessariamente tem que ter um comportamento na parte sexual como, como um, um heterossexual masculino". E15 declara que "gênero [é] 
independente da sexualidade" e E16 afirma que masculino é algo "independente de opção sexual, seja opção homossexual ou heterossexual”.

Dessa forma, a solidez da masculinidade apontada por Mees (2005) e tão presente na modernidade se dilui. A masculinidade deixa de significar algo bruto, durável, heterossexual e estável, sendo que sua suavização se inscreve também no corpo. Para Cabistani (2005), na contemporaneidade, ocorre um rompimento das sólidas fronteiras estabelecidas pela modernidade entre masculino e feminino. Assim, cada vez mais o masculino incorpora o feminino e vice-versa. Conforme Amaral (2005) esclarece, não é a anatomia dos órgãos genitais que constitui masculinidade e feminilidade, pois masculino e feminino não são opostos e excludentes e misturam-se nos sujeitos, permitindo aos homens "circular entre o feminino e o masculino" (Amaral, 2005, p. 96).

Por fim, as mudanças na vida doméstica e na clássica divisão entre espaço público e privado em função de gênero têm produzido alterações na concepção da masculinidade. Em relação ao espaço privado masculino, não significa mais que o homem "vai ser o dono da casa, vai ser o chefe da casa, que vai ser o que vai ganhar mais, já tá mais liberado" (E08). E09 esclarece que há divisão de tarefas e funções na esfera privada e homens têm ocupado uma "posição compartilhada com a mulher". Interessante observar que os entrevistados afirmam que as mudanças na divisão do trabalho também ocorreram na vida privada e não somente na pública, como escrevem Boltanski e Chiapello (2009). O enunciado do trabalhador E11 é bem esclarecedor em relação a essa modificação:

"o homem não podia participar do ambiente de casa com a mulher e hoje a grande maioria dos homens fazem coisas dentro de casa pra ajudar as esposas, pra ajudar a limpar banheiro, ajudar no trato com os filhos, no trato com a família, antigamente isso era impossível".

Contudo, apesar do maior compartilhamento das tarefas e maior participação dos homens no espaço privado, isso não significa que não exista divisão de funções fundamentadas em aspectos de gênero dentro do espaço doméstico. O que acontece é que a clássica concepção moderna, com suas certezas absolutas e sólidas, pelas quais o espaço público pertenceria a homens, e o privado, a mulheres, está se desfazendo (Mees, 2005). Desta forma, observa-se que as mudanças no masculino têm demonstrado que sua solidez concebida na modernidade está abalada. Entretanto, apesar da suavização e rompimento com fronteiras anteriormente estabelecidas, isso não significa que o masculino se tornou mais frágil ou que perdeu hegemonia ou potência. Apesar das diferentes e novas formas de expressões, a masculinidade ainda atua e exerce funções centrais e potentes em relação à divisão do trabalho e na construção de hierarquias sociais no ambiente laboral, conforme será analisado nos tópicos a seguir.

\section{Aspectos diretamente relacionados ao trabalho}

Para Foucault (2003), o importante em uma análise do discurso é evidenciar a função que um enunciado exerce em um determinado tempo e espaço. O tempo histórico é o contemporâneo e o espaço analisado situa-se no setor minerossiderúrgico da grande Vitória. Desta forma, buscou-se entender a função exercida pelos enunciados sobre a masculinidade em suas relações com o trabalho exercido no setor minerossiderúrgico, ou seja, em suas relações com acontecimentos econômicos (trabalho) e institucionais (minerossiderúrgico). Portanto a primeira questão a ser respondida é: qual a função exercida pela masculinidade no contexto estudado?

Dos discursos analisados, pode-se concluir que a masculinidade tem a principal função de definir as possíveis performances de gênero a serem desempenhadas nos espaços público e privado. Apesar da maior fluidez, visibilidade e presença da masculinidade no espaço privado, conforme constatado na sessão anterior, isso não significa que a masculinidade deixou de atuar como elemento organizador e regulador sobre o que se pode desempenhar, tanto no espaço público quanto no privado. Os trabalhadores entendem que esta nova forma de divisão das tarefas não limita a atuação do masculino ou feminino em espaços público ou privado. 
“outra coisa é a possibilidade dele [homem] não trabalhar e da mulher trabalhar, isso é muito complicado na cabeça do homem da minha época e hoje você já percebe homens que não trabalham ou ganham menos.... Mas eu conheço uns que não trabalham realmente, e sem nenhuma dificuldade de estar em casa, como a mulher ficou uma época, essas possibilidades permitem uma expressão melhor, eu acho, da gente". (E16).

Tanto as mulheres saíram da vida doméstica para a pública quanto os homens saíram da pública para a privada (Amaral, 2005). Gutmann e Vigoya (2004) demonstram que esta divisão espacial tem se modificado muito nos últimos anos, com o crescimento das taxas educacionais das mulheres, fato que as torna qualificadas para o trabalho e para buscar exercer as atividades laborais para as quais estão qualificadas. Entretanto Connell (2004) esclarece que, apesar dessa maior participação das mulheres na vida pública, a maioria delas ainda exerce tarefa fortemente relacionada com os afazeres domésticos e ao ato de cuidar. Isso reforça uma divisão de trabalho no seio das organizações, em que gênero não restringe mais o acesso a espaços públicos ou privados, mas passa a ser definidor do que se pode executar dentro de cada um destes espaços.

Neste sentido, gênero não atua mais como um muro divisor que impediria a atuação do masculino no espaço privado e do feminino no espaço público e vice-versa, mas passou a exercer a função de definidor do que se pode e deve desempenhar internamente nesses espaços. Sobre isso, apesar do crescimento relatado pelos trabalhadores do número de mulheres no setor, uma das barreiras de acesso impostas às mulheres é o fato de a maior parte das tarefas não ter relação direta com atividades domésticas. Conforme relata E17: "A gente se assustava quando via uma mulher trabalhando é... em mecânica, ou trabalhava dirigindo caminhão". E17 ainda complementa que "hoje nessa empresa onde eu trabalho, eu vejo algumas [destas] posições sendo ocupadas também por mulheres".

Por um lado, verifica-se que se mudanças sobre a divisão do trabalho têm ocorrido, por outro lado, a divisão do trabalho nas organizações, nas quais os entrevistados estão inseridos, tem se modificado em uma velocidade mais lenta e cautelosa do que no ambiente privado/doméstico, principalmente, quando estão em jogo os cargos de níveis gerenciais e estratégicos das organizações minerossiderúrgicas. Em outras palavras, a clássica divisão entre concepção e execução do trabalho passou a ser uma função exercida pelo masculino, na qual a produção e consumo de masculinidade são vistos como essenciais para o exercício das atividades de comando ou de concepção do trabalho.

Conforme E17 relatou, nessa nova divisão do trabalho, as mulheres executam atividades consideradas exigentes de força física, contudo continuam sendo, principalmente, consideradas como desprovidas ou deficientes de masculinidade (Ahl \& Marlow, 2012) para exercerem atividades de concepção e comando do trabalho, ficando elas mais com atividades de execução. Ou seja, houve apenas uma expansão das atividades que as mulheres podem executar para além das consideradas frágeis ou domésticas, mas elas ainda são impedidas de ocupar cargos de decisão no alto escalão das organizações estudadas. Sobre isto, E06 afirma que "são dois supervisores e 14 gerentes, 16 gerentes, no caso gerentes de fábrica, todos são homens, gerente geral é homem, existe uma gerente no departamento jurídico". E05 acrescenta que: "Ah! Gerencia, supervisão, a maioria é homem e, a princípio, heterossexuais, porque eu não conheço a sexualidade deles. Ah mulheres, como eu falei, tem muito pouco. Supervisora aí que eu sei menos ainda".

Assim, apesar de as mulheres estarem ocupando e executando atividades anteriormente vistas como tipicamente masculinas, a proporcionalidade de cargos entre homens e mulheres não é tão igualitária, e quanto maior o nível hierárquico, mais se aprofunda esse abismo. Vale também ressaltar que apesar de algumas mulheres estarem exercendo atividades laborais consideradas brutas e pesadas, as mesmas ainda são vistas como frágeis por muitos entrevistados, conforme será demonstrado adiante. Para melhor esclarecer tais afirmativas, serão analisadas, a seguir, as implicações da masculinidade na construção de hierarquias sociais no trabalho minerossiderúrgico, principalmente o preconceito e discriminação direcionados a contratação e divisão do trabalho. Em outras palavras, a masculinidade atua como um nó na rede social, econômica e institucional, assim, produzindo, no ambiente laboral, hierarquias sociais sobre a capacidade de se executar determinadas tarefas e exercer cargos. 
Em relação à igualdade entre homens, mulheres e homossexuais no trabalho, E06 afirma que: "Homossexuais, eu não diria.... Mais homem e mulher sim, contudo, porque, por exemplo, a gente não tem hoje aqui nenhuma mulher como técnica". Já E15 afirma que "[em relação a mulheres e homossexuais] Eu acho que existe um discurso [de igualdade], mas a prática não, existe um discurso muito grande" (E15). Mulheres ainda não conseguem ocupar, em igualdade numérica, os postos de trabalho ofertados, sendo dificultado o acesso a algumas posições consideradas estratégicas nestas organizações, principalmente atividades técnicas, engenharias, gerenciais e de direção. E11 enfatiza que "na minha empresa, é um número muito baixo de mulheres realmente no cargo de engenharia, no cargo de supervisão, de gerencia, de diretoria". Isso explica um fato ocorrido durante o procedimento de produção de dados da pesquisa: a grande dificuldade de se conseguir mulheres para serem entrevistadas de forma igualmente proporcional ao número de homens.

Ao se perguntar para os entrevistados se o sexo das pessoas influencia na contratação, alguns sujeitos pesquisados responderam que não, mas se observou, quando os entrevistados responderam outras questões da entrevista, que, na visão da maioria dos trabalhadores, o sexo influencia diretamente na contratação, conforme E02 afirma "como a área de mecânica é uma área braçal, por ser homem é mais fácil". E09 acha "que a empresa, ela dá oportunidade para ambos os sexos, agora tem lugares que mulher não tem condições de ir, de exercer a função. Agora nos locais que é possível, sempre tem uma mulher, duas... três". O entrevistado E15 relata: "na época que eu fui contratado, em 1986, acredito que seria, principalmente pra função que eu exerço, a engenharia é uma função... Eu acho que a maior parte..., ainda hoje, é mais homens". Sobre este aspecto, E03 acredita que

“Apesar de hoje terem contratado uma técnica, uma técnica de segurança, ela não vai tá mandando, ela vai tá totalmente operacional, ela vai tá um pouco administrativa, na área mesmo só tem homem, então é... é mais propicio que homem trabalhe".

Contudo, quando a pergunta é se as atividades exercidas pelos trabalhadores são masculinas ou não, as respostas são interessantes e até de certa forma antagônicas com a baixa presença de mulheres. Dos 20 entrevistados, nove afirmaram que, de forma geral, as atividades desenvolvidas pelos trabalhadores do setor minerossiderúrgico são tipicamente masculinas, sendo que 11 trabalhadores acreditam que é uma atividade nem masculina, nem feminina, ou seja, poderia ser executada por qualquer pessoa independente de gênero. Observa-se que nenhum entrevistado afirmou que o trabalho realizado é tipicamente feminino, nem mesmo as mulheres entrevistadas. Os trabalhadores apenas mencionaram algumas tarefas específicas como sendo femininas, principalmente tarefas relacionadas ao "cuidar e organizar", como, por exemplo, relatada pela entrevistada E15:

"tanto do sexo masculino como do sexo feminino, o que se fala é que por ser uma área da qualidade, meio ambiente e saúde, segurança e, as mulheres, nós, sexo feminino o que a gente é mais organizada, então, a gente tem até muito mais visão e é mais cuidadosa com tudo isso".

Segundo Connell (2004), existe no mercado de trabalho um estereótipo cultural em que as mulheres são vistas como menos racionais que os homens, estes tomados como seres completamente racionais. Ora, conforme salienta Jerusalinsky (2005), a masculinidade pode ser exercida tanto por homens quanto por mulheres, e não é a anatomia em si que define a masculinidade. A divisão binária entre masculino e feminino e a consequente separação e exclusão da presença de aspectos femininos em homens, tanto quanto masculinos em mulheres, colabora para a criação do que Holter (2004) chama de hierarquia de gênero, a qual certo tipo de masculinidade, entre as diversas masculinidades existentes, ocupa uma posição privilegiada em relação às demais masculinidades e feminilidades.

As características culturais atribuídas ao feminino e a consequente atribuição dessas características às mulheres acabam criando um estereotipo cultural de que mulher é algo frágil, sem habilidade para exercer atividades diretamente relacionadas com o processo produtivo, considerado, pelos sujeitos, como muito pesado, destinando às mulheres atividades relacionadas a organizar e cuidar, conforme salientado por E11: 
“É, numa parte ajuda, porque aqui às vezes mulheres têm aquele mais detalhe, pelo mesmo trabalho que a gente faz aqui dentro, que é montagem. Então mulher tem aquele jeitinho a mais, que, às vezes, nos detalhes o homem não... não percebe".

Entretanto vale ressaltar que os trabalhadores pesquisados estão em empresas reconhecidas como tendo um alto nível de mecanização, ou seja, as tarefas que exigem maior esforço físico são realizadas por maquinários desenvolvidos para esta finalidade. Plummer (2004) demonstra claramente que essas atitudes, vinculadas ao estereótipo sexual, contribuem para a legitimação de comportamentos também estereotipados de homens e mulheres, assim, estigmatizando que nada nos homens deva ser feminino, como, por exemplo, cuidar, ser emocional e passivo, reforçando ainda mais que o gênero dos homens é oposto ao das mulheres. Porém nenhuma pessoa representa este modelo hegemônico em sua totalidade, pois todos nós apresentamos em nossas práticas diárias aspectos tanto femininos quanto masculinos, independentemente de sermos homens ou mulheres (Amaral, 2005).

Em relação ao exercício da sexualidade e sua influência na contratação de pessoas para trabalharem no setor estudado, os entrevistados reconhecem que há alguma relação entre esses dois fatores, principalmente para gays que têm traços femininos evidentes, ou seja, a menor produção e consumo de masculinidade tem a função de produzir diferença entre sujeitos. $O$ interessante é que isso foi relatado não apenas pelos trabalhadores que se declararam homossexuais, mas também pelos empregados heterossexuais, como, por exemplo, afirmado por E13: "Creio que sim, uma grande maioria é hetero, creio que influencia sim". Desta forma, gênero apresenta contornos próprios em espaços diferentes. Quando definem masculinidade na sociedade de forma geral sem um contexto local específico, os trabalhadores afirmam que não existe incoerência entre masculinidade e homossexualidade. Contudo, quando contextualizada no ambiente de trabalho estudado, a homossexualidade passa a ser significada como presença do feminino, ou seja, homossexualidade significa ausência de masculino. Existe claramente uma hierarquia social no trabalho entre as práticas sexuais. Nesta hierarquia, qualquer sexualidade que rompa com a heterossexualidade passa a ser vista como uma questão de minorias, ocorrendo uma marginalização destes sujeitos (Souza \& Pereira, 2013).

Verifica-se que existe ainda muito preconceito e discriminação em contratar pessoas gays, principalmente homens homossexuais que apresentem características femininas. Apesar de a homossexualidade não ser algo simplesmente detectado por este atributo, pois práticas homossexuais nem sempre têm relação com a existência de traços femininos em evidência, pois muitos homossexuais não possuem esta característica, fato que lhes garante uma invisibilidade social no processo de contratação e o acesso ao emprego, conforme relatado por E16: "Na época que fui contratado, uma mulher nunca seria contratada pra ser gerente de pátio, um homossexual enrustido... Talvez!".

Isto nos faz acreditar que homens que não tenham traços femininos passem despercebidos, o que os torna menos vulneráveis à discriminação na contratação. Além disso, observam-se duas diferenças no tratamento dado aos homossexuais e às mulheres na contratação pelas empresas: (a) mulheres contratadas para cargos técnicos e de engenharia ainda é algo revestido de muitos cuidados e preconceitos; (b) homossexuais acabam sendo contratados para cargos técnicos de forma mais frequente que mulheres, contudo, em relação aos cargos gerenciais e de direção, se constatada a homossexualidade, eles são considerados não aptos para seu exercício.

Quando questionados de forma direta sobre eventuais discriminações sofridas no ambiente de trabalho, a maioria dos entrevistados afirmou que não sofreu nenhum tipo de discriminação. Apenas três entrevistados assumiram que já sofreram discriminação no trabalho, dois homens e uma mulher. Um deles declarou-se homossexual, e os outros dois, heterossexuais. Segundo os homens entrevistados, os motivos da discriminação sofrida têm relação com: (a) possuir traços de gênero considerados femininos pelos colegas (homem heterossexual) e (b) homossexualidade (homem homossexual). Vale salientar que o conceito de masculinidade estabelece relações de poder não somente entre homens e mulheres, mas também entre os próprios homens e as próprias mulheres (Collinson \& Hearn, 2004). Já a trabalhadora afirmou que foi discriminada por dois motivos: ser mulher e ter a pele negra. 
Quando indagados sobre brincadeiras no ambiente de trabalho, os entrevistados afirmaram que é muito comum rotular colegas de trabalho considerados educados e bonitos como homossexuais, mesmo quando não o sejam. Aliás, conforme já abordado, discriminar homens pelo fato de serem educados e bonitos revela a existência de diversas masculinidades dentro do espaço organizacional e o status menor conferido às masculinidades consideradas não hegemônicas (Connell, 1987; Holter, 2004).

Também, quando questionados sobre discriminações sofridas no trabalho, os entrevistados demonstraram grande desconforto. Observou-se que tinham certo receio em responder a essa questão, com medo de que seus discursos pudessem chegar aos gestores das organizações em que trabalham. Assim, na dúvida sobre as eventuais repercussões de suas respostas, preferiram manifestar o discurso oficial das organizações, conforme relato pelo E07:

"Eu... eu gostaria de fazer uma separação... eu acho o seguinte: pela, pela... pela empresa, pela estrutura, vamos falar formal, não há discriminação quanto a isso certo. Agora pelas pessoas existe a discriminação. Então, eu não vejo uma discriminação da empresa assim, muito pelo contrário, os gerentes evitam qualquer... e até hierarquicamente você não percebe muito isso. Mas eu acho que no fundo existe".

Para eles, não existe discriminação por parte das políticas oficiais e normas da empresa, ou seja, elas não têm uma postura oficial formal em seus regulamentos que incentive ou proteja atos discriminatórios. Vale ressaltar que o E11 relatou que as discriminações não ocorrem dentro da empresa, mas sim fora dela.

\section{Conclusões}

A crise do masculino refere-se às mudanças atinentes aos atributos culturais relacionados a gênero, ou seja, sendo gênero algo relacional, qualquer mudança no masculino também provoca alterações no feminino (Amaral, 2005; Vasconcelos et al., 2004). Verificou-se que na contemporaneidade atributos como sensibilidade, polidez e educação estão presentes na construção e definição de masculinidade, fato que demonstra uma suavização do masculino em relação aos atributos de épocas atrás. Pode-se até afirmar que o masculino possui muito mais conteúdos femininos nos dias de hoje do que em épocas passadas. Contudo esta conclusão só pode ser feita quando temos presente em nossas mentes e vidas os modelos masculino e feminino que emergiram da modernidade, ou seja, a crise do masculino não eliminou antigos modelos de gênero. Aliás, esses modelos ainda se apresentam como hegemônicos no ambiente de trabalho estudado.

Observou-se que tem ocorrido mudanças em relação à divisão de trabalho entre homens e mulheres, contudo elas se dão de forma mais acelerada na vida privada do que no ambiente de trabalho. Nas entrevistas analisadas, é atribuída a mulheres, gays efeminados e homens heterossexuais que apresentem atributos femininos uma incapacidade laboral na execução de determinadas atividades. Neste aspecto, a masculinidade exerce a função de produzir diferenças no nó da rede social, econômica e institucional pelas quais os cargos de decisão e concepção são considerados mais adequados para sujeitos que produzem e consomem masculinidade. Os trabalhadores, no caso, ainda relacionam feminilidade à fragilidade e o exercício de trabalhos relacionados apenas com a execução de tarefas e não a cargos de comando. Desta forma, apesar da crise do masculino (Brooks, 2010; Knights \& Tullberg, 2011), modelos de masculinidade tradicionais são extremamente valorizados no ambiente de trabalho estudado, afirmando uma desvalorização do feminino e criando hierarquias não somente entre homens e mulheres, mas também entre homens, atribuindo menor status às masculinidades não hegemônicas.

Em função disso, poucas mulheres são contratadas para exercerem, principalmente, cargos técnicos, bem como vinculados às engenharias, funções gerenciais e de direção. Homossexuais, quando contratados, ocupam funções técnicas, entretanto, similarmente às mulheres, para cargos gerenciais e de direção são considerados não aptos para seu exercício. Portanto estes trabalhadores ainda sofrem preconceitos e discriminações relacionadas a gênero em empresas do setor minerossiderúrgico. Os atos discriminatórios referem-se a ações ou omissões normalmente fundamentadas em estereótipos. Em 
relação aos atos discriminatórios, eles ocorrem de forma mais explícita fora do ambiente da empresa. Masculino e feminino não são opostos, mas constituem-se mutuamente (Muraro, 2007; Prasad, 2012). Assim, qualquer alteração no masculino provoca mudanças no feminino. Portanto, como sugestões para futuras pesquisas, seria interessante analisar como a crise do masculino tem afetado e provocado possíveis mudanças no feminino. Será que a feminização do masculino implica necessariamente em uma masculinização do feminino? Ou seja, será que o feminino se masculinizou? Esta é uma questão relevante e pouco explorada nos estudos organizacionais.

Dessa maneira, este artigo evidencia contribuições no conhecimento das temáticas aqui tratadas, no sentido de que reforça a tendência a uma tensão na construção social entre os gêneros masculino e feminino no mundo do trabalho do setor minerossiderúrgico. Foi possível demonstrar-se uma suavização na construção social do masculino no que diz respeito a conteúdos menos relacionados a concepções como comportamentos machistas em relação às mulheres, ao relacionamento social de forma dominadora e agressiva, bem como às ações de cunho autoritário, atos típicos do universo masculino até então tidos como estáveis. Entretanto, ao mesmo tempo e paradoxalmente, aspectos da construção do masculino ainda se manifestam como ativos no presente, como é o caso da manutenção de uma hierarquização, na qual modelos tradicionais institucionalizados do universo masculino ainda prevalecem, por meio de uma reserva de cargos de direção e de decisão, reafirmando a supremacia dos atributos masculinos, bem como a discriminação de gays e mulheres para ocupação daqueles cargos.

Pode estar aí se registrando uma reinvenção do próprio masculino, sem a perda de sua importância na hierarquia social. Nessa reinvenção, pode estar em consolidação uma provável percepção do que se entende por masculino, na contemporaneidade, com relação ao que se tinha como estável e socialmente bem delimitado, em especial no setor minerossiderúrgico aqui estudado. Em outras palavras, como se pode enriquecer o conhecimento sobre o agir e o verbalizar aquilo que se entende por masculinidade e feminilidade nas relações de trabalho? Como os sujeitos, em seu agir cotidiano, distanciam-se daquilo que, por ventura, verbalizam em seus discursos baseados em suas crenças e valores? Em quais contextos, contradições, paradoxos, inconsistências entre o agir e o verbalizar se manifestam? Eis alguns desafios para futuras pesquisas sobre a crise do masculino! Por fim, como limitação da pesquisa, o fato de a maioria dos entrevistados ser da mesma classe social (classe média) e trabalhar em empresas de grande porte, com políticas de recursos humanos que seguem modelos internacionais sobre diversidade, pode ter influenciado os seus discursos.

\section{Nota}

${ }^{1}$ Pesquisa realizada com financiamento da Fundação de Amparo à Pesquisa do Espírito Santo (FAPES).

\section{Referências}

Ahl, H., \& Marlow, S. (2012). Exploring the dynamics of gender, feminism and entrepreneurship: advancing debate to escape a dead end? Organization, 19(5), 543-562, doi: $10.1177 / 1350508412448695$

Alexandersson, M. (1994). Method and consciousness. Goteborg: Acta Univesitatis Gothoburgensis.

Alves, M., Brito, M. J. M., Melo, M. C. O. L., Lemos, L. P., \& Ferreira, M. A. (2008, maio). Práticas de gestão, relações de poder e de gênero na organização hospitalar. Anais do Encontro de Estudos Organizacionais da ANPAD, Belo Horizonte, MG, Brasil, 5.

Amaral, I. E. (2005). Corpo e sexo: masculinidade feminilidade. In Associação Psicanalítica de Porto Alegre, Masculinidade em crise (pp. 85-98). Porto Alegre: Autor.

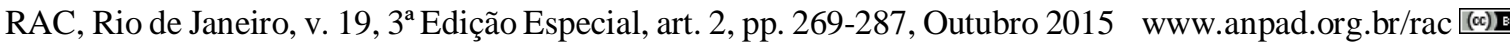


Bauman, Z. (2001). Modernidade líquida. Rio de Janeiro: Jorge Zahar Editora.

Billing, Y. D. (2011). Are women in management victims of the phantom of the male norm? Gender, Work and Organization, 18(3), 298-317, doi: 10.1111/j.1468-0432.2010.00546.x

Boltanski, L., \& Chiapello, E. (2009). O novo espírito do capitalismo. São Paulo: WMF Martins Fontes.

Bordieu, P. (2010). A dominação masculina. Rio de Janeiro: Bertrand Brasil.

Braverman, H. (1987). Trabalho e capital monopolista: a degradação do trabalho no século XX. Rio de Janeiro: Guanabara.

Brooks, G. R. (2010). Beyond the crisis of masculinity: a transtheoretical model for male-friendly therapy. Washington: American Psychological Association.

Cabistani, R. M. O. (2005). A liberdade de escolher entre a bolsa e a vida: (des)caminhos da sexuação. In Associação Psicanalítica de Porto Alegre, Masculinidade em crise (pp. 63-72). Porto Alegre: Autor.

Collinson, D. L., \& Hearn, J. (2004). Men and masculinities in work, organizations, and management. In M. S. Kimmel, J. Hearn, \& R. W. Connell (Eds.), Handbook of studies on men \& masculinities (pp. 289-310). California: Sage Publications.

Connell, R. W. (1987). Gender and power: society, the person, and sexual politics. California: Stanford University Press.

Connell, R. W. (1995). Masculinities. Cambridge: Polity.

Connell, R. W. (2004). Globalization, imperialism, and masculinities. In M. S. Kimmel, J. Hearn, \& R. W. Connell (Eds.), Handbook of studies on men \& masculinities (pp. 71-89). California: Sage Publications.

Cramer, L. (2009, setembro). Relações de gênero, poder e profissão em organizações hospitalares: um enfoque sócioconstrucionista. Anais do Encontro Nacional da Associação Nacional de PósGraduação e Pesquisa em Administração, São Paulo, SP, Brasil, 33.

Cupolilo, F. B. N. (2008, setembro). Como se faz um Tijucano? Reflexões sobre consumo, identidade e masculinidade em um bairro carioca. Anais do Encontro Nacional da Associação Nacional de Pós-Graduação e Pesquisa em Administração, Rio de Janeiro, RJ, Brasil, 32.

Davidovitsch, L., \& Silva, J. F. (2008, maio). Implicações da percepção dos calores simbólicos das roupas: gênero masculino em foco. Anais do Encontro de Marketing da ANPAD, Curitiba, PR, Brasil, 3.

Devreux, A.-M. (2005). A teoria das relações sociais de sexo: um quadro de análise sobre a dominação masculina. Sociedade e Estado, 20(3), 561-584. doi: 10.1590/S0102-69922005000300004

Eccel, C. S., \& Grisci, C. L. I. (2011). Trabalho e gênero: a produção de masculinidades na perspectiva de homens e mulheres. Cadernos EBAPE.BR, 9(1), 57-78. Recuperado de http://www.scielo.br/pdf/cebape/v9n1/v9n1a05.pdf. doi: 10.1590/S1679-39512011000100005

Eccel, C. S., \& Grisci, C. L. I. (2010, maio). Trabalho, gênero e subjetividade: a valorização dos engenheiros em uma empresa do setor petroquímico. Anais do Encontro de Estudos Organizacionais da ANPAD, Florianópolis, SC, Brasil, 6.

Edwards, T. (2004). Queering the pitch? Gay masculinities. In M. S. Kmmel, J. Hearn, \& R. W. Connell (Eds.), Handbook of studies on men \& masculinities (pp. 51-68). California: Sage Publications. 
Ekenstam, C., Johansson, T., \& Kuosmanen, J. (2001). Cracks in the facade: masculinities in transition. Stockholm: Gidlunds.

Fontes, O. A., Borelli, F. C., \& Casotti, L. M. (2010, setembro). Como ser homem e ser belo? Um estudo exploratório sobre práticas masculinas de consumo de beleza. Anais do Encontro Nacional da Associação Nacional de Pós-Graduação e Pesquisa em Administração, Rio de Janeiro, RJ, Brasil, 34.

Foucault, M. (1988). História da sexualidade I: a vontade de saber. Rio de Janeiro: Edições Graal.

Foucault, M. (1996). Entrevista com Michel Foucault, por Sérgio P. Rouanet e J. G. Merquior. In M. Foucault, S. P. Rouanet, J. G. Merquior, D. Lecourt, \& C. H. Escobar (Orgs.), O homem e o discurso: a arqueologia de Michel Foucault (pp. 17-42). Rio de Janeiro: Edições Tempo Brasileiro.

Foucault, M. (2003). A ordem do discurso. São Paulo: Edições Loyola.

Glaser, B. G., \& Strauss, A. L. (1967). The discovery of grounded theory: strategies for qualitative research. Chicago: Aldine.

Gutmann, M. C., \& Vigoya, M. V. (2004). Masculinities in Latin America. In M. S. Kimmel, J. Hearn, \& R. W. Connell (Eds.), Handbook of studies on men \& masculinities (pp. 114-128). California: Sage Publications.

Holter, O. G. (2004). Social theories for researching men and masculinities: direct gender hierarchy and structural inequality. In M. S. Kimmel, J. Hearn, \& R. W. Connell (Eds.), Handbook of studies on men \& masculinities (pp. 15-29). California: Sage Publications.

Jerusalinsky, A. (2005). Qual o sexo de Oscar Wilde? In Associação Psicanalítica de Porto Alegre, Masculinidade em crise (pp. 15-29). Porto Alegre: Autor.

Knights, D., \& Tullberg, M. (2011). Managing masculinity/mismanaging the corporation. Organization, 19(4), 385-404. doi: 10.1177/1350508411408170

Mathieu, C. (2009). Practising gender in organizations: the critical gap between practical and discursive consciousness. Management Learning, 40(2), 177-193. doi: 10.1177/1350507608101229

Medeiros, C. R. O., \& Valadão, V. M., Jr. (2009, setembro). Masculinidade e feminilidade na AMEAS: holograma, ilhas de caridade ou uma selva desconhecida. Anais do Encontro Nacional da Associação Nacional de Pós-Graduação e Pesquisa em Administração, São Paulo, SP, Brasil, 33.

Mees, L. A. (2005). O Don Juan líquido ou a histericização do masculino. In Associação Psicanalítica de Porto Alegre, Masculinidade em crise (pp. 152-161). Porto Alegre: Autor.

Minayo, M. C. S., Deslandes, S. F., Cruz, O., Neto, \& Gomes, R. (1994). Pesquisa social: teoria, método e criatividade. Petrópolis: Vozes.

Morrell, R., \& Swart, S. (2004). Men in the third world: postcolonial perspectives on masculinity. In M. S. Kimmel, J. Hearn, \& R. W. Connell (Eds.). Handbook of studies on men \& masculinities (pp. 90-113). California: Sage Publications.

Muraro, R. M. (2007). História do masculino e do feminino. Rio de Janeiro: ZIT.

Nolasco, S. (1993). O mito da masculinidade. Rio de Janeiro: Rocco. 
Oliveira, A. M. D. C. M. (2008). Masculinidade e pós-modernidade: a imagem do homem e o fim das grandes narrativas. In M. I. Ghilardi-Lucena \& F. Oliveira (Orgs.), Representações do masculino: mídia, literatura e sociedade (pp. 41-62). Campinas: Alínea.

Plummer, K. (2004). Male sexualities. In M. S. Kimmel, J. Hearn, \& R. W. Connell (Orgs.), Handbook of studies on men \& masculinities (pp. 178-195). California: Sage Publications.

Prasad, A. (2012). Beyond analytical dichotomies. Human Relations, 65(5), 567-595. doi: $10.1177 / 0018726711432183$

Robinson, S. (2000) Marked men: white masculinity in crises. New York: Columbia University Press.

Sauerbronn, J. F. R. (2007, setembro). Vergonha e consumo - uma investigação das relações entre consumo masculino e o sentimento de vergonha. Anais do Encontro Nacional da Associação Nacional de Pós-Graduação e Pesquisa em Administração, Rio de Janeiro, RJ, Brasil, 31.

Scott, J. (1990). Gênero: uma categoria útil de análise histórica. Educação e Realidade, 16(2), 5-22.

Souza, E. M., Corvino, M. M. F., \& Lopes, B. C. (2013). Uma análise dos estudos sobre o feminino e as mulheres na área de administração: a produção científica brasileira entre 2000 a 2010. Organizações \& Sociedade, 20(67), 603-621. Recuperado de http://www.scielo.br/pdf/osoc/v20n67/a03v20n67.pdf. doi: 10.1590/S198492302013000400003

Souza, E. M., \& Pereira, S. J. N. (2013). (Re)produção do heterossexismo e da heteronormatividade nas relações de trabalho: a discriminação de homossexuais por homossexuais. Revista de Administração Mackenzie, 14(4), 76-105. Recuperado de http://editorarevistas.mackenzie.br/index.php/RAM/article/view/3668/4439. doi: 10.1590/S1678-69712013000400004

Vasconcelos, I. F. G., Vasconcelos, F. C., \& Mascarenhas, A. O. (2004). Batom, pó de arroz e microchips: o falso paradoxo entre as dimensões masculina e feminina nas organizações e a gestão de pessoas. Revista Organizações \& Sociedade, 11(31), 119-133.

Veiga, R. T., \& Matos, E. B. (2008, setembro). Um estudo da diferença entre gêneros em relação à intenção do uso de preservativo a partir da teoria do comportamento planejado. Anais do Encontro Nacional da Associação Nacional de Pós-Graduação e Pesquisa em Administração, Rio de Janeiro, RJ, Brasil, 32.

Vilas Boas, L. H. B. de, Paula, A., Neto, \& Cramer, L. (2003). Relações de gênero nas organizações: um estudo no setor de vendas de veículos. Revista de Administração da Universidade de São Paulo, 38(3), 219-229.

\title{
Dados dos Autores
}

\author{
Eloísio Moulin de Souza \\ Av. Fernando Ferrari, 514, Campus Goiabeiras, 29075-910, Vitória, ES, Brasil. E-mail: eloisiomoulin@ gmail.com \\ Mônica de Fatima Bianco \\ Av. Fernando Ferrari, 514, Campus Goiabeiras, 29075-910, Vitória, ES, Brasil. E-mail: mofbianco@ gmail.com \\ Gelson Silva Junquilho \\ Av. Fernando Ferrari, 514, Campus Goiabeiras, 29075-910, Vitória, ES, Brasil. E-mail: gelsonufes@ gmail.com
}

